\title{
Benjamin e o marxismo
}

Leandro Konder

Para tentarmos entender melhor como se estabeleceu a relação de Walter Benjamin com o marxismo e o que o marxismo representou para ele, não podemos, certamente, nos limitar à história de amor com Asja Lacis, a combativa militante comunista letoniana, mulher do diretor teatral alemão Bernhard Reich. Benjamin se apaixonou por ela, os dois estiveram juntos na Itália, em seguida ele foi vê-la em Riga, depois foi visitá-la em Moscou, quando ela estava internada numa clínica para doentes nervosos (como se dizia naquele tempo).

Por mais interessante que seja, essa história de um amor infeliz - como costumavam ser os amores benjaminianos - não nos esclarece a respeito da interpretação dada por Benjamin às idéias pelas quais as conversas com Asja Lacis o levaram a se interessar.

Até hoje, não se sabe com certeza quais os textos de Marx e Engels que Benjamin leu com atenção e na íntegra. Seus escritos e sua correspondência, entretanto, deixam claro que, em meados dos anos 1920, ele leu História e consciência de classe, de Georg Lukács, e ficou indelevelmente marcado pelo livro.

Desde o seu primeiro contato com o marxismo, portanto, Benjamin se entusiasmou por uma linha de interpretação do pensamento de Marx que divergia das versões doutrinárias adotadas tanto pelo establishment social-democrático como pela direção do movimento comunista.

O que Benjamin encontra no marxismo não é tanto um sistema conceitual constituído, sólido, maciço, mas um admirável conjunto de conceitos que já surgem vocacionados para radicalizar a crítica à sociedade burguesa e para impulsionar a revolução contra o capitalismo. Um conjunto de conceitos que proporcionam ao sujeito magníficas armas para ele se inserir na luta de classes.

O que mais agrada na perspectiva nova que Marx lhe apresenta (via Lukács) é exatamente o fato de que ela recusa a postura daqueles que se encastelam no plano da teoria e aponta insistentemente para a fecundidade teórica da própria prática ou, ao menos, da prática revolucionária. 
O marxismo, então, não era e não podia ser uma construção teórica que proporcionaria a quem a adotasse um elenco de respostas prontas, "corretas", para todas as questões. Benjamin o entendia como um poderoso estímulo ao mergulho na ação, na convicção de que esse mergulho é que lhe permitiria descobrir novas dimensões significativas na realidade que estava empenhado em transformar.

Essa maneira de entender o marxismo não se manifestou, na época, unicamente em Lukács e em Benjamin: com características e traços bastante variados, ela aparece também, um tanto tumultuadamente, em alguns momentos, no pensamento do italiano Antonio Gramsci, em determinados escritos de Theodor Wiesengrund Adorno, no ensaio "Teoria tradicional e teoria crítica" de Max Horkheimer, em diversos textos de Karl Korsch e de Ernst Bloch.

Outra, contudo, foi a "leitura" que prevaleceu no movimento histórico dos marxistas, em geral. No âmbito da socialdemocracia, o "marxismo" veio a ser um sistema montado a partir de um conjunto articulado de citações dos "clássicos" (Marx e Engels), consideradas essenciais pelo zelador "oficial" do legado doutrinário, o alemão Karl Kautsky. A "montagem”, de resto, se fazia com base numa linha "evolucionista" da interpretação da história.

No âmbito do movimento comunista, o marxismo passou a ser o "marxismo-leninismo", um outro conjunto (mais "duro") de citações dos "clássicos" (Marx, Engels e Lênin) consideradas essenciais pela direção política dos partidos, definidora da "linha justa” (Stálin).

Em ambos os casos, havia uma combinação de elementos que compunham uma concepção da história na qual determinados sujeitos assumiam as responsabilidades da iniciativa política e a massa dos liderados era convencida a segui-los em nome da necessidade histórica inexorável. (As divergências giravam em torno de quais eram os "condutores" do processo e de qual deveria ser a velocidade das transformações).

Em ambos os casos, havia um rígido "controle" da doutrina estruturada como um todo sobre a "correta" aplicação dos conceitos.

O saudoso Nelson Werneck Sodré, uma vez, criou brincalhonamente uma expressão adequada para a caracterização do procedimento instituidor de "ortodoxias": havia autoridades teóricas que aplicavam aos textos um rigoroso "marxímetro". 
Havia, nessas concepções do marxismo, um evidente sacrifício da dimensão filosófica do pensamento de Marx, não só da dialética, mas também daquele que vem sendo reconhecido atualmente como o conceito mais original e mais fundamental da filosofia de Marx: o conceito de práxis.

Nos anos 1920 e 1930, a importância do conceito de práxis não era reconhecida, em geral. É verdade que Gramsci reagiu contra essa subestimação e insistiu em chamar o marxismo de "filosofia da práxis"; mas Gramsci logo ficou isolado, encarcerado por Mussolini, impossibilitado de exercer uma efetiva influência nos debates internos do movimento comunista. Sua influência, afinal, foi póstuma, só se tornou marcante com a publicação de Cadernos do cárcere, no pósGuerra, depois de 1945 (Gramsci, como sabemos, morreu em 1937).

O conceito de práxis abre caminho para que seja repensada a relação teoria/prática. A prática "pede" teoria, precisa de teoria, porém nada assegura que ela vai receber sempre uma teoria que corresponda plenamente à sua demanda. $\mathrm{E}$ a teoria só pode corresponder plenamente a essa demanda se se integrar à prática que a solicitou, participando dela.

A práxis é a atividade por meio da qual a teoria se integra à prática, "mordendo-a", e a prática "educa" e "reeduca" a teoria.

Benjamin não dedicou nenhum dos seus escritos ao conceito de práxis. No entanto, o horizonte permanente do seu marxismo, mesmo que isso não tenha sido explicitado, era o do conceito de práxis.

Ao contrário de Lukács, o admirado autor de História e consciência de classe, e de Adorno, que na segunda metade dos anos 1920 se tornou um de seus principais interlocutores, Benjamin, na juventude, antes do seu encontro com o marxismo, já tinha tido a experiência da atividade política, participando do movimento estudantil em Berlim. Para nós, aqui, considerado o nosso objetivo neste artigo, não importa que a atividade política do jovem Benjamin tenha sido confusa, ou mesmo crassamente equivocada (como no Movimento da Juventude Livre Alemã, Freideusche Jugendbervegung); o que importa é que ele viveu a experiência da atividade política, que Lukács e Adorno não viveram.

Essa experiência imprimiu desde cedo à assimilação do marxismo por Benjamin uma feição peculiar. Para o nosso autor, 
as condições históricas do século XX mostravam no capitalismo uma capacidade de resistência maior do que Marx, genial pensador do século XIX, poderia imaginar.

O capitalismo desenvolveu recursos extremamente poderosos de manipulação do comportamento, conferiu notável poder de persuasão às ideologias que correspondiam aos seus interesses vitais, fortaleceu-se consideravelmente, e o marxismo benjaminiano tratou de extrair as conseqüências da convicção de que o capitalismo não iria "morrer de morte natural".

Não havia, portanto, nenhuma garantia possível para assegurar que as contradições objetivas do capitalismo, objetivamente, ao se agravarem, provocariam o colapso (Zusammenbruch) do "sistema". Nenhuma dinâmica sócioeconômica "inexorável" faria por si mesma aquilo que os revolucionários eram desafiados a fazer: tomar as iniciativas políticas necessárias para liquidar o modo de produção inventado pela burguesia, substituindo-o por um novo modo de produção, compatível com as aspirações do movimento operário e, em última análise, com as aspirações da humanidade.

Enquanto a doutrina do marxismo, em sua versão socialdemocrática, alimentava na consciência dos trabalhadores a ilusão de que eles estavam na crista da onda do movimento histórico sócioeconômico, cultivando neles a convicção de que o marxismo era a "ciência" que observava e descrevia o que já estava acontecendo, o marxismo de Benjamin se voltava para as tensões da práxis, da atividade criadora voltada para o que ainda não aconteceu.

Aos socialdemocratas Benjamin preferia os comunistas. Tratava-se, entretanto, de uma opção miserável.

Convencido de que os comunistas, na prática, faziam algumas coisas que precisavam ser feitas, o filósofo nem por isso se identificava com eles.

Em diversas ocasiões, expressou mesmo claras discordâncias em relação às concepções que eles adotavam. Basta lembrarmos a controvérsia em torno do verbete "Goethe", redigido por Benjamin para a Enciclopédia Soviética e severamente submetido a cortes e adulterações pela direção da publicação.

O "marxismo-leninismo", tal como foi codificado pela direção que sucedeu a Lênin (leia-se Stálin), parecia-lhe altamente problemático. Irritava-o, contudo, a pretensa "flexibilidade" com que os seguidores da doutrina, reiterando sempre 
uma estrita fidelidade a ela, adaptavam-na pragmaticamente às circunstâncias. Achava lamentável vê-los acenar com rupturas impossíveis e preconizar a aceitação de continuidadesinaceitáveis.

Não podia deixar de se insurgir contra o uso demagógico, oportunista, de conceitos como progresso, civilização, evolução e desenvolvimento. Preocupava-se em cobrar de quem os utilizasse uma explicitação dos limites e do conteúdo atribuído a cada termo, no contexto da sua utilização.

Se a história fosse um processo linear evolutivo, subordinado aos ditames de um tempo homogêneo e vazio, os sujeitos humanos não teriam como intervir nele. Nossos projetos seriam vãos, inócuos. Benjamin repelia o determinismo rígido e a resignação dele decorrente.

Para ele, se o determinismo prevalecesse, o balanço das nossas perdas se degradaria num inventário estúpido, porque não haveria nada a resgatar no passado. $\mathrm{E}$ a revolta perderia todo e qualquer sentido: reduzir-se-ia a mera insensatez.

Inspirava-lhe também uma forte repulsa a expansão, em escala mundial, de procedimentos de tipo relativista, que implicavam conivência com a redução tendencial de todos os autênticos valores humanos (absolutos) a critérios quantificadores (isto é, aos preços de mercado). Essa redução dos valores qualitativos a cifras era, a seu ver, uma decorrência da centralidade do mercado, típica do modo de produção capitalista.

Embora não possamos saber ao certo se Benjamin leu todo O capital, de Marx, é fácil percebermos que ele tomou conhecimento da análise marxiana do fetichismo da mercadoria.

Se todas as coisas tendem a se transformar em mercadorias, se a própria força humana de trabalho (a criatividade dos homens!) é vendida por um salário, onde podem ser enxergados os sujeitos humanos, aqueles que transformam o mundo e se transformam a si mesmos?

Dostoiévski disse que se Deus não existe tudo é permitido. A ideologia dominante no capitalismo poderia dizer: se o sujeito humano não existe, tudo é vendável, tudo pode ser objeto de compra e venda. E os sujeitos humanos, cada vez mais, estão sumindo; uns desaparecem nas grandes empresas, nas sociedades anônimas; outros somem atrás dos objetos mercadorias, que mostram possuir uma visibilidade bem maior do que nós.

Benjamin se horroriza com a onda de cinismo que acompanha a proliferação dos relativismos. Para enfrentar politica- 
mente o problema político com que se defronta, o filósofo procura mobilizar os saberes disponíveis. Verifica, porém, que as mais diversas áreas da produção científica estão infiltradas pela relativização amolecedora.

É então que a teologia lhe aparece como um bastião da resistência, já que seu objeto - Deus - não pode deixar de ser o absoluto, o não-relativo por excelência.

Benjamin mergulhou, assim, na leitura dos teólogos e dos místicos, em especial no estudo de teólogos e místicos heterodoxos. A referência ao absoluto torna concreto o relativo. Ela torna possível para nós uma compreensão mais profunda da história.

Em vez de pretendermos reconstituir o passado tal como ele pretensamente teria sido, nos damos conta de que exercitamos nosso poder de rememoração a partir do presente.

Se tem algum sentido falarmos na "totalidade" do tempo histórico, cabe-nos estar bem atentos para o fato de que essa compreensão - sempre provisória - será fundada pela intensidade da experiência vivida no tempo-de-agora (Jetztzeit). Nossa vida, sustenta o filósofo, é um músculo que tem força suficiente para contrair o tempo histórico em sua totalidade.

O tempo, no conhecimento histórico, é reconhecido como incompleto, inacabado.

Os lutadores do passado, aqueles que nos precederam na rebeldia, nos enviam sinais, que precisamos captar, para alimentarmos a débil força messiânica que nos foi concedida. A dimensão de continuidade na história (hegemonia conservadora) tem prevalecido e continua prevalecendo sobre a ruptura. O que precisamos fazer, então? Benjamin responde: escovar a história a contrapelo.

Só uma autêntica revolução pode canalizar com eficiência todas as energias libertárias, numa iluminação profana, capaz de recuperar - simbolicamente - tudo que foi desejado com grandeza pelos rebeldes do passado. Só uma verdadeira revolução pode redimir os que foram injustamente derrotados, através de uma apocatástase histórica.

A atribuição à história de um sentido objetivamente dado é um artifício ideológico que visa impedir que os sujeitos se sintam postos diante de uma história que está em aberto e cujo "sentido" será aquele que eles lhe conferirem.

Nada é definitivo, irrevogável. "Cada segundo", diz Benjamin, "é a porta estreita por onde o Messias pode entrar". E a única 
possibilidade de que a história venha a ser julgada está no Dia do Juízo Final.

A essa altura da nossa exposição do movimento do pensamento de Benjamin em sua relação com o marxismo, é bem possível que o leitor esteja convencido de que a perspectiva benjaminiana, a partir de certo ponto, decididamente abandona o terreno da sua relação com o marxismo.

Em sua visão da religião, as posições de Benjamin e Marx não são só diferentes: são opostas.

Para Marx, a consciência religiosa era a consciência alienada por excelência. "A religião é o suspiro da criatura esmagada, o sentimento caloroso de um mundo sem coração, o espírito de um mundo sem espírito"* Quando, no comunismo, as relações entre os homens e deles com a natureza se tornarem racionais e transparentes, o reflexo da realidade na consciência não precisará mais da religião, segundo Marx (no terceiro volume de $O$ Capital), e a religião desaparecerá*.

Benjamin, contudo, podia se perguntar: esse é o núcleo essencial da perspectiva de Marx? Esse é o fundamento insubstituível do marxismo? E, se é, é a base de qual marxismo?

Nos anos 1930, havia diversos marxismos em confronto, às vezes em franco conflito. Benjamin podia se apoiar numa construção teórica própria, original, e reivindicar para ela um caráter ou uma inspiração marxista.

Michael Löwy ministrou durante um ano todo um curso dedicado às Teses sobre o conceito de História, de Benjamin, e observou que o nosso ensaísta tinha clareza a respeito de suas divergências com Marx, porém evitava manifestá-las e preferia criticar os expoentes dos marxismos do século XX, seus contemporâneos, porque estava convencido de que devia a Marx o essencial da sua perspectiva: a compreensão da práxis na luta de classes.

Seu modo de ser marxista não exigia que ele se mantivesse preso ao que Marx pensara e escrevera, mas cobrava dele que retomasse os conceitos e os desenvolvesse no âmbito de uma continuação da luta, aprofundando e corrigindo a teoria em função das necessidades novas reveladas pela práxis.

O Dia do Juízo Final, a apocatástase histórica, a revoluçãoredenção e o Messias que pode entrar a qualquer momento pela porta estreita do tempo não têm nada a ver com a rigorosa sobriedade de Marx, ateu convicto, materialista inabalável.
"(Marx-Engels-Werke., vol. 1 Berlin: Dietz, 1967: 379)

"(Marx-Engels-Werke, vol. 26 Op. cit.: 94) 
" (Löwy, Michael. Walter Benjamin: avertissement d'incendie. Paris: Presses Universitaires de France, 2001.)
Marx era antimessiânico. Benjamin, contudo, poderia argumentar que o seu messianismo aparecia não propriamente para contestar o ponto de vista de Marx sobre a religião, mas para fortalecer o projeto político de Marx.

Michael Löwy chama a nossa atenção para a novidade do messianismo benjaminiano: "Deus está ausente e a tarefa messiânica está inteiramente nas mãos das gerações humanas. $\mathrm{O}$ único Messias possível é coletivo, é a própria humanidade. Mais precisamente, a humanidade oprimida"*

Na perspectiva de Marx, segundo Benjamin, o proletariado faria a revolução e a revolução corresponderia às aspirações e aos anseios de liberdade e justiça de praticamente toda a humanidade, sobretudo dos explorados. Benjamin tendia a pensar as duas coisas - a luta de classes vivida pelos trabalhadores e a mobilização ampla da humanidade oprimida - em uma conexão bastante imediata, muito direta.

Via com agrado seu amigo comunista Bertolt Brecht declarar que não tinha sentido prolongar além de limites razoáveis discussões teóricas muito complicadas, muito sofisticadas. Brecht dizia que, em nome das urgências da ação, há sempre um momento no qual é preciso chegar a uma formulação rude, "grosseira" (plumpes Denken). Benjamin gostava dessa idéia.

Impacientava-se com as elaboradíssimas articulações dialéticas que caracterizavam os trabalhos de seu amigo Adorno. Respeitava-o, não queria polemizar com ele publicamente, mas com certeza não se dispunha, pessoalmente, a acompanhá-lo em seu estilo de pensamento.

Adorno, nos anos 1930, era provavelmente melhor dialético e mais rigorosamente marxista do que Benjamin. Mas não mostrava partilhar com ele a forte disposição para intervir ativamente na luta de classes. Nesse aspecto, Benjamin estava mais próximo do espírito de Marx do que Adorno.

Benjamin sabia da necessidade de pensar agindo, de agir pensando. Procurava um caminho para atuar politicamente. Tinha lido Maquiavel, portanto tinha consciência de que não basta você expressar suas convicções, não é suficiente expor com clareza suas idéias: é necessário enxergar os caminhos possíveis para traduzi-las em ação, e trilhá-los de modo a fazê-las prevalecer.

Durante alguns anos, o nosso autor alimentou o projeto de ingressar no Partido Comunista, organização que lhe pro- 
porcionaria condições para a atividade militante. Anunciou mais de uma vez a seu amigo Gershom Scholem, teólogo judeu, que, "por uma questão de coerência", entraria para o partido. Mas nunca entrou.

Não seguiu o caminho de Lukács, que ingressou na organização e nela permaneceu, enfrentando mil dificuldades, sobrevivendo a mil tempestades, fazendo autocríticas e concessões penosas, ao longo de mais de meio século.

Também não seguiu o caminho de Adorno, intelectual que trabalhava com um pequeno grupo, se mantinha isolado, desconfiado de tudo e de todos, confiando apenas na sua implacável "dialética negativa”, sem fazer concessões à "positividade", quer dizer, sem se comprometer com as experiências políticas vividas (e sofridas) por socialistas e comunistas.

Benjamin, de fato, nunca conseguiu resolver esse problema; nunca descobriu o trajeto que o levaria à participação prática, direta, na luta de classes.

Em que ficamos, então?

Walter Benjamin era ou não era marxista?

O que era, afinal, esse marxismo benjaminiano, tão povoado de categorias místicas e de conceitos da teologia judaica?

Quem foi, precisamente, esse autor: um filósofo travestido de teólogo ou um teólogo travestido de filósofo? Ou, como sugere Michael Löwy, foi filósofo e também foi teólogo?

Diante dessas indagações, eu me pergunto: "Não valeria mais a pena nós indagarmos: o que um marxista teria de mais importante a aprender, a repensar, com a obra de Walter Benjamin?" 


\section{Leandro Konder}

Professor da Pós-Graduação da PUC-Rio. Autor de inúmeros livros, dentre os quais: Walter Benjamin: o marxismo da melancolia (Civilização Brasileira), Por que Marx? (Graal), O futuro da filosofia da práxis: o pensamento de Marx no século XXI(Paz e Terra), Marx: vida e obra (Paz e Terra) e Lukács e a atualidade do marxismo (Boitempo Editorial).

Palavras-chave Walter Benjamin marxismo messianismo

Keywords Walter Benjamin Marxism messianism

\section{Resumo}

O objetivo deste artigo é discutir a relação que as idéias de Walter Benjamin mantêm com o marxismo. Para Benjamin, as condições históricas do século XX mostravam no capitalismo uma capacidade de resistência maior do que Marx poderia imaginar: a práxis opõe-se na realidade a uma teorização radical dos socialdemocratas. A maior oposição, entretanto, capaz de separar os dois pensamentos, é a visão messiânica presente na filosofia de Walter Benjamin: mas o verdadeiro Messias acaba por ser a própria humanidade. Benjamin seria filósofo, teólogo ou um teórico que ajudaria a repensar o próprio marxismo?

\section{Abstract}

The purpose of this article is to discuss the relationship between Walter Benjamin and Marxism. For Benjamin, $\mathrm{XX}^{\text {th }}$ century's historic conditions showed in capitalism a greater capacity for resistance than Marx imagined to be possible: praxis opposes itself to the radical theorization of the Social Democrats. The greatest opposition, however, which separates these two thinkers, is the messianic vision of Walter Benjamin's philosophy: but the real Messiah ends up being humanity itself. Would Benjamin then be a philosopher, a theologian or rather a theorist who helps us to reflect upon Marxism itself?

\section{Résumé}

Le but de cet article est de discuter la relation que les idées de Walter Benjamin maintiennent avec le marxisme. Pour Benjamin, les conditions historiques du $\mathrm{XX}^{\mathrm{e}}$ siècle révélaient dans le capitalisme une capacité de résistance plus grande que celle que Marx aurait pu imaginer: la praxis s'opposant à la théorisation radicale des sociaux-démocrates. La plus grande opposition, cependant, capable de séparer les deux penseurs, c'est la vision messianique de la philosophie de Walter Benjamin: mais le vrai Messie finit par être l'humanité elle-même. Benjamin serait alors un philosophe, un theólogien ou plutôt un théoricien qui aiderait à penser le marxisme lui-même? 